\title{
Short interfering RNA induced generation and translation of stable 5' mRNA cleavage intermediates
}

\author{
Richa Singhania ${ }^{1}$, Sandra Pavey ${ }^{1}$, Elizabeth Payne ${ }^{1}$, Wenyi Gu${ }^{1}$, Jennifer Clancy ${ }^{2}$, Luqman \\ Jubair $^{3}$, Thomas Preiss ${ }^{2}$, Nicholas Saunders ${ }^{1}$, Nigel A.J. McMillan ${ }^{1,3}$,*
}

${ }^{1}$ The University of Queensland Diamantina Institute, University of Queensland, Brisbane, Australia

${ }^{2}$ The John Curtin School of Medical Research, The Australian National University, Canberra, Australia

${ }^{3}$ Menzies Health Institute Queensland and School of Medical Science, Griffith University, Southport, Australia.

* Corresponding Author

Email: n.mcmillan@griffith.edu.au 


\section{Abstract}

Sequence-specific degradation of homologous mRNA is the main mechanism by which short-interfering RNAs (siRNAs) suppress gene expression. Generally, it is assumed that the mRNA fragments resulting from Ago-2 cleavage are rapidly degraded, thus making the transcript translation-incompetent. However, the molecular mechanisms involved in the postcleavage mRNA decay are not completely understood and the fate of cleavage intermediates has been poorly studied. Using specific siRNAs and short-hairpin RNAs (shRNAs) we show that the 5' and 3' mRNA cleavage fragments of human papilloma virus type 16 (HPV-16) E6/7 mRNA, over-expressed in cervical malignancies, are unevenly degraded. Intriguingly, the 5' mRNA fragment was more abundant and displayed a greater stability than the corresponding 3' mRNA fragment in RNAi-treated cells. Further analysis revealed that the 5' mRNA fragment was polysome-associated, indicating its active translation, and this was further confirmed by using tagged E7 protein to show that C-terminally truncated proteins were produced in treated cells. Overall, our findings provide new insight into the degradation of siRNA-targeted transcripts and show that RNAi can alter protein expression in cells as a result of preferential stabilization and translation of the 5' cleavage fragment. These results challenge the current model of siRNAmediated RNAi and provide a significant step forward towards understanding non-canonical pathways of siRNA gene silencing.

\section{Highlights}

- RNA interference does not result in the immediate degradation of mRNA following cleavage

- The 5' cleavage product of mRNA has a longer half-life than the 3' product

- The 5' cleavage product is translated into truncated protein

- Cleavage can occur on the ribosome during translation.

Keywords: siRNA, shRNA, RNAi, mRNA cleavage, mRNA decay 


\section{Introduction}

Gene expression in eukaryotes is governed by the relative rates of mRNA transcription, translation and degradation. There is mounting evidence to show that small RNAs are key modulators of eukaryotic gene expression. The transcriptional and post-transcriptional regulatory pathways orchestrated by various small RNAs are collectively termed as RNA interference (RNAi) or gene silencing. To date, many species of small RNAs have been described and the list continues to expand. Short-interfering RNAs (siRNAs) are $\sim 21$ nucleotide long RNA molecules that interfere with the expression of cytoplasmic mRNAs by mediating endonucleolytic cleavage (1). Functional siRNAs can either be delivered into the cell cytoplasm extracellularly or else generated intracellularly by Dicer-processing of short-hairpin RNAs (shRNAs). The posttranscriptional gene silencing mediated by siRNA relies on the combined outcome of the reduction in the target mRNA transcripts and the repression of translation of encoded protein. Firstly, the siRNA duplex unwinds and the guide strand associates with Argonaute 2 (Ago2) protein, and together they form core of the effector complex known as the RNA-induced silencing complex (RISC). Next, the siRISC is recruited to the target mRNA transcript through base-pairing interactions and ultimately interferes with the target protein expression by causing mRNA cleavage and decay (2). Although, their origin and mechanism of action are well characterized, molecular details of post-cleavage mRNA decay remain to be fully elucidated. In this study we have attempted to explore the downstream events of siRNA-mediated mRNA cleavage.

Our current understanding of siRNA action is that the slicer activity of Ago2 in siRISC directs the cleavage of target mRNA between $10^{\text {th }}$ and $11^{\text {th }}$ nucleotide of the base paired region (2) and as a result, a capped 5' and a poly(A) tailed 3' mRNA fragment will be created, each bearing an unprotected end. The RNAi cleavage fragments are targeted by the general cellular mRNA degradation machinery for complete destruction from their exposed ends (3). There are two major conserved mRNA degradation pathways in eukaryotes, which are initiated by shortening of the poly(A) tail. Deadenylated mRNAs can either be digested by the 3'-to-5' exonuclease activity of a multisubunit complex called the exosome, or else can undergo DCP1/2directed decapping prior to being degraded in a 5' -to-3' direction by the XRN1 exonuclease (4). This would suggest a model for siRNA-cleaved mRNAs whereby the 5' cleavage fragment is 
degraded by the exosome from its free 3' end while the 3' cleavage fragment is degraded by XRN1 from its free 5'end. Experimental evidence supports this model with knockdown studies in Drosophila showing that the 5' fragment is a substrate for 3'-to-5' exonuclease activity of the exosome (5). Perfectly matching miRNAs mimic siRNA action to mediate target mRNA cleavage and sometimes in such instances the 5' cleavage fragment is modified by the addition of a tail of uridines or adenosines at the site of cleavage in order to accelerate the exosomemediated decay (6). Loss of XRN1 in Drosophila S2 cells leads to stabilization of the 3' fragment (5). Similarly, loss of XRN4, a plant homolog of XRN1, leads to accumulation of the 3' miRNA cleavage product in Arabidopsis (7).

In eukaryotic cells, sub-microscopic cytoplasmic foci known as processing or P-bodies (PBs, also referred to as GW-bodies) are considered to be major sites of mRNA turnover. These mRNP granules arise due to accumulation of RNA-binding proteins, mRNA decay factors, but are devoid of translation factors (except eIF4E) and ribosomes $(8,9)$. It is now evident that PBs serve as intracellular sites for RNAi $(10,11)$, suggesting that RISC activation and the execution of terminating steps of RNAi pathway occur in PBs. Although PB environment offers a kinetic advantage, they are not essential for the execution of RNAi (12). PBs do not participate in translation (13), however, they are not dead ends. Some of the translationally inactive mRNPs may be committed to immediate decapping and degradation (14) while the rest may exit to associate with polysomes and resume translation (15). The ability of mRNA to exist in dynamic equilibrium between a translationally active state (polysomes) and a translationally repressed state (PBs) suggests that these processes are interconnected (16).

In mammalian cells mRNA degradation has been observed to be neither rapid nor complete with siRNA-mediated cleavage reported to result in the generation of partially stable 5' or 3' mRNA fragments (17-20). Indeed, we have previously shown that truncated proteins can be translated from the 5' end of shRNA-targeted mRNA (21). However, the details by which cleaved products can result in truncated proteins remain unclear.

The link between mRNA abundance, stability, and translation remains to be clearly elucidated in the presence of a siRNA stimulus. Therefore, the purpose of the current study was to investigate the fate of siRNA-generated mRNA cleavage fragments and understand how si/shRNA influences the steady-state levels, half-lives and translation status of the cleavage 
intermediates. Using the human papillomavirus type 16 (HPV-16) E6/7 mRNA as a model, we report that siRNA-generated 5' mRNA fragment had higher steady-state levels and was found to persist longer than the 3' mRNA fragment. Moreover, 5' cleavage intermediates were present in polysomes and were translated to produce truncated E7 protein products. Our findings help to understand the molecular consequences of siRNA knockdown and highlight a previously uncharacterised decay pathway of cleavage intermediates that may alter the therapeutic outcomes of RNAi.

\section{Materials and Methods}

Cell culture - TC-1 and CaSki cells (from the ATCC) were maintained in DMEM (Invitrogen) supplemented with 10\% heat-inactivated fetal calf serum (Sigma) and 1\% antibiotic mixture of penicillin G, streptomycin sulfate and L-Glutamine (Gibco-Invitrogen).

Plasmid transfection - The FLAG-E7-MYC sequence was cloned into pJ204 (DNA 2.0, CA) and then sub-cloned into pcDNA3 as a HindIII-EcoRI fragment. Cells were transiently transfected with the construct using Lipofectamine 2000 (Invitrogen), according to manufacturer's instructions.

siRNA transfection and shRNA lentiviral transduction - Cells were transiently transfected with $40 \mathrm{nM}$ siRNA duplexes (Integrated DNA Technologies) using Oligofectamine (Invitrogen), as per manufacturer's protocol. The shRNA expression cassettes were cloned into pLentiLox3.7 (pLL) vector to generate stable cell lines. Transduction efficiency was determined by FACSCanto flow cytometer (BD Biosciences) and GFP positive cells sorted using MoFlo cell sorter (Beckman Coulter). The sequences of the siRNAs and shRNAs are listed in Table S1.

Semiquantitative RT-PCR - PCR was performed in $25 \mu \mathrm{L}$ volume consisting of PCR buffer $(10 \mathrm{X})$, dNTP mix $(10 \mu \mathrm{M})$, primers $(10 \mu \mathrm{M})$, Taq DNA polymerase, and cDNA (1:10 dilution) under the following PCR profile: $5 \mathrm{~min}$ initial denaturation at $95^{\circ} \mathrm{C}$, followed by 20 cycles of denaturation $\left(94^{\circ} \mathrm{C}\right)$, annealing $\left(58-62^{\circ} \mathrm{C}\right)$ and extension $\left(72^{\circ} \mathrm{C}\right)$, plus a final extension at $72^{\circ} \mathrm{C}$ for $5 \mathrm{~min}$. DNA was electrophoresed $\mathrm{n} 1.5 \%$ agarose gel and visualized by UV transillumination.

Quantitative RT-PCR ( $q P C R)$ - Total RNA was prepared from cells using the TRIzol ${ }^{\circledR}$ reagent (Invitrogen) according to the manufacturer's protocol. Reverse transcription reaction was carried out on DNase-treated RNA using Omniscript reverse transcription kit (Qiagen). The 
resulting cDNA was amplified with gene-specific primers (Table S2) and quantified using FastStart Universal SYBR Green (Roche Applied Science) on AB 7900HT real-time PCR system (Applied Biosystems). Comparative $\mathrm{Ct}(\Delta \Delta \mathrm{Ct})$ method was used for performing relative quantitation of gene expression. Absolute quantitation was done by comparing the $\mathrm{Ct}$ values of samples with a standard curve generated by known amounts of pcDNA3-HPV16 and pCMV6GAPDH-GFP plasmids.

$m R N A$ half-life estimation - Total RNA was extracted from cells harvested at different time points post actinomycin $\mathrm{D}(5 \mu \mathrm{g} / \mathrm{mL})$ treatment and reverse transcribed into cDNA. The amount of mRNA at each time point was analyzed by qPCR and expressed as a percentage of the total amount of mRNA at time 0 and was plotted against time. The data was analyzed by exponential non-linear regression (one-phase decay) analysis to determine the best-fit line. Halflives were determined by extrapolating the best fit line to the point where it crosses the $50 \%$ mRNA onto the $\mathrm{X}$ axis.

Polysome analysis - Cells were treated with $100 \mu \mathrm{g} / \mathrm{mL}$ cycloheximide for $3 \mathrm{~min}$ and lysed in a buffer containing 20mM HEPES (pH 7.6), $125 \mathrm{mM} \mathrm{KCl}$ and $5 \mathrm{mM} \mathrm{MgCl}_{2}, 2 \mathrm{mM}$ DTT, 0.5mM PMSF, 100 units/mL of RNase inhibitor, $0.5 \% \mathrm{NP} 40,100 \mu \mathrm{g} / \mathrm{mL} \mathrm{CHX}$ and cocktail of protease inhibitors on ice. Cell lysates were fractionated on a $17.5-50 \%(\mathrm{w} / \mathrm{v})$ sucrose gradient, followed by centrifugation in SW41Ti rotor at 35,000 r.p.m. for $2 \mathrm{~h} 15 \mathrm{~min}$ (22). The gradient was fractionated on a density gradient fractionator (Teledyne ISCO) and polysome profiles were monitored by UV absorbance at $254 \mathrm{~nm}$. To analyse the mRNA distribution on polysomes, RNA extracted from each gradient fraction was subjected to qPCR.

Stem loop qPCR - Reverse transcription (RT) reactions were carried out using $500 \mathrm{ng}$ of RNA along with $1 X$ RT buffer, $0.25 \mathrm{mM}$ dNTPs, $0.3 \mathrm{U} / \mu \mathrm{L}$ reverse transcriptase, $0.25 \mathrm{U} / \mu \mathrm{L}$ RNase inhibitor and $50 \mathrm{nM}$ stem loop RT primer (23) and successively incubated for $30 \mathrm{~min}$ at $16^{\circ} \mathrm{C}, 30 \mathrm{~min}$ at $42^{\circ} \mathrm{C}$ and $5 \mathrm{~min}$ at $85^{\circ} \mathrm{C}$. The $\mathrm{RT}$ product was amplified with $1 \mathrm{X}$ Taqman universal PCR master mix (Applied Biosystems), 0.2 M Taqman probe, 1.5 $\mu \mathrm{M}$ forward primer and $0.7 \mu \mathrm{M}$ reverse primer using standard qPCR thermal profile and performed on an $\mathrm{AB}$ 7900HT real-time PCR system (Applied Biosystems). The sequences of probes and primers are listed in Table S3.

Immunofluorescence - Transfected cells were fixed with $4 \%$ paraformaldehyde for 30 min, washed and permeabilized with $0.1 \%$ Triton X-100. Cells were immunolabelled using 
fluorescently conjugated antibodies against FLAG and MYC tags (1:200; Alexa Fluor 555 and 647 conjugates, respectively; Cell Signaling Technologies) and incubated along with DAPI (1:1000). Coverslips were mounted using ProLong Gold (Invitrogen), observed with Zeiss LSM510 laser scanning confocal microscope (Carl Zeiss) under a $\times 63$ oil objective and analyzed by ImageJ software.

Western Blotting. Twenty-four hrs after transfection cells were treated with MG132 for 14 hours before lysis in RIPA buffer and Halt protease inhibitor (Thermo Scientific). Extracts were incubated for $60 \mathrm{~min}$ at $4^{\circ} \mathrm{C}$ with mouse anti-FLAG Tag (Cell Signaling Technologies) before A/G magnetic beads (BioLabs) were added an incubation continued overnight. Following washing proteins were solubilised SDS loading buffer and run on $16 \%$ Tris-tricine gels before transfer and detection using rabbit monoclonal anti-flag primary antibody (Cell Signaling Technologies).

Statistics. Data are presented as mean or mean \pm standard error of the mean (SEM). An unpaired Student's t-test (two-tailed, $\mathrm{p} \leq 0.05$ ) was used to determine statistically significant differences.

\section{Results}

RNAi cleavage results in preferential degradation of the 3' $m R N A$ fragment. RNAi efficiency, as measured by the loss of full-length target mRNA, does not allow one to determine the potential presence and abundance of the resulting 5' and 3' mRNA cleavage products. To explore the fate of mRNA cleavage fragments generated following shRNA treatment, we utilized two shRNAs targeting the HPV-16 E6/7 mRNA, shE6 and shE7 (21) and a range of PCR primer pairs specific to various regions of the mRNA (Fig 1A). The E6/7 mRNA was highly reduced in TC-1 cells (murine cells transform with Ras, and E6/7) stably expressing each shRNA, as reported by the full-length PCR amplicon 1 (Fig. 1B). However, utilising primers specific to the 5' and 3' ends of the mRNA (amplicons 2 and 3, respectively) we observed a different outcome. The 5' and 3' ends of E6/7 mRNA showed levels of reduction much less than the full-length mRNA upon shE6 and shE7 treatment, while cells treated with control shRNA (shNS-1) showed no effect (Fig. 1B). This suggested that specific shRNA treatment results in delayed degradation of the cleaved mRNA in mammalian cells. Analysis using quantitative reverse transcription 
PCR (qPCR) using specific 5' and 3' end primer sets matched for size and amplification efficiency confirmed that unequal degradation of the cleavage fragments was occuring (Fig. 1C). We observed that the 5' fragment (amplicon 4) had higher steady-state levels compared to the 3' fragment (amplicon 5) and the slice-site specific mRNA (amplicons 6/7). The same outcome was observed with E7 specific siRNAs (Figure S1), indicating that this was not a shRNA-only phenomenon.

In order to understand the degradation events in more detail we next used PCR amplicons targeting regions within each predicted fragment (amplicons 4, 6 and 8 for 5' fragment and amplicons 8, 7 and 9 for 3' fragment). Using shE7 as the most 3' target site, the 5' fragment appeared to be degraded in the 3'-5' direction given the reduced length of the 3' amplicons 6 and 8 compared to the 5' fragment of amplicon 4. (Fig. 1D). Upon shE6 treatment, mRNA levels reported by amplicons 8 and 9 are much less abundant than those reported by amplicon 7 , suggesting that the 3' fragment is subjected to dual degradation in both 5'-to-3' as well as 3'-to5' direction (Fig. 1E).

The 5' fragment is longer-lived than the 3' $m R N A$ fragment. As abundance only reflects a snapshot of steady state mRNA levels, we next examined the half-lives $\left(\mathrm{t}_{1 / 2}\right)$ of mRNA fragments following si/shRNA cleavage. The mRNA decay was monitored in cells harvested at various time-points post actinomycin D treatment by qPCR using 5' end (amplicon 4) and 3' end (amplicon 5) primer sets. The E6/7 mRNA exhibited a $t_{1 / 2}$ of $\sim 5$ hours in control shRNA-treated cells (Fig. 2A), consistent with previous reports $(24,25)$. Treatment with E6/7-specific shRNAs resulted in a 2-3-fold decrease in the $t_{1 / 2}$ of full-length mRNA (Fig. 2A). In non-specific shRNAtreated cells the apparent $\mathrm{t}_{1 / 2}$ reported by 5' and 3' specific amplicons were similar, $\sim 5 \mathrm{~h}$ (Fig. 2B) and was in agreement with the $\mathrm{t}_{1 / 2}$ of full-length mRNA. Strikingly, the 5 ' $\mathrm{mRNA}$ fragment exhibited a $\mathrm{t}_{1 / 2}$ almost twice as long as the ${ }^{\prime}$ ' mRNA fragment in cells treated with specific shRNAs (Fig. 2C). Treatment with E7 specific siRNAs yielded similar results (Figure S2). To our knowledge this is the first study highlighting $t_{1 / 2}$ differences between the products of si/shRNA endonucleolytic cleavage in mammalian cells.

The 5' mRNA fragment is associated with polysomes. One consequence of the relative stability of the 5' mRNA fragment is the potential for translation to occur. To investigate this, mRNA distribution on polysomes was analysed by density sucrose gradients. After a brief treatment with cycloheximide $(\mathrm{CHX})$, cytoplasmic extracts of TC-1 cells were centrifuged 
through 17.5-50\% gradients and RNA samples recovered from polysome fractions were analysed by qPCR to estimate the levels of 5' and 3' mRNA fragments. The sedimentation profiles of CHX-exposed control and shE6-treated cells showed that most of the mRNA-ribosome complexes were distributed in the polysome-bound fractions (Fig. 3A). Upon treatment with shE6 we observed that the 5' end of the E6/7 mRNA was associated with translating ribosomes but the 3' end could not be detected (Fig. 3C). This was a specific effect as both mRNA ends could be detected when non-specific shRNA was used (Fig. 3B).

Controls to confirm whether mRNA was associated with polysomes, by preparing cell lysates in the presence of EDTA indicated the majority of $\beta$-actin mRNA, which served as an internal experimental control, was concentrated in the non-translating monosomal fractions (Figure S3). We found that the full-length E6/7 mRNA was bound to less number of ribosomes, consistent with its shorter length and its translation efficiency was reduced upon specific shRNA treatment (Figure S4).

The specific 5' mRNA fragment is present in total and polysomal RNA - To provide direct evidence that the 5' fragment present in polysomes was the specific, shE6-directed 5' cleavage product rather than a consequence of a random degradation event, we undertook a Taqman-based stem-loop RT-PCR assay, originally described for detection of miRNA (23) and siRNA (26) molecules (Fig. 4A). In this method, a stem-loop primer binds to the specific 5' cleavage product at the 3' cleavage site and primes reverse transcription. To ensure only the specific shRNAgenerated cleavage product was detected; a Taqman qPCR was performed using an E6/7-specific forward primer, a probe spanning the specific ligation site, and a loop-specific reverse primer. Using this assay we were able to detect the specific 5' cleavage product only in the total and polysomal RNA samples obtained from cells treated with shE6 but not in control cells (Fig. 4B). Overall, polysome and stem-loop Taqman qPCR analyses showed that the specific 5' shE6cleavage intermediate co-sedimented with polysomes, suggesting active translation.

C-terminally truncated proteins are expressed after RNAi treatment - Finally, to establish a direct link between the generation and translation of 5' cleavage fragments, we created a construct that expressed an in-frame FLAG tag at the 5' end of the HPV16 E7 gene and a MYC tag at the 3' end (Fig. 5A), so that the FLAG and MYC tags serve as surrogate markers for the N and C-termini of the E7 protein, respectively. We hypothesized that upon shRNA cleavage overall E7 protein levels would decrease but there would be a higher expression of FLAG tag 
compared to MYC tag due to the postulated translation from the 5' end of mRNA. Cells were treated with MG132 in order to block potential proteasomal turnover of truncated proteins (27). Using antibodies against FLAG and MYC, we observed a similar intensity of FLAG and MYC signals in untreated and control shRNA (shNS-1 and shNS-2) treated cells (Fig. 5B). In shE7 treated cells, while the overall levels of E7 protein was reduced, there was a marked difference in the FLAG/MYC intensity with a shift towards FLAG signal intensity (Fig. 5B). Since E7 protein is mainly localized in the nucleus (28), nuclear fluorescence intensities were measured. The ratio of mean nuclear intensities of FLAG signal over MYC signal was close to 1 in control cells but in shE7 treated cells, the ratio increased to more than 2 (Fig. 5C), reflecting preferential translation of the 5' end of E7 mRNA. Similar experiments using siRNAs against E7 resulted in the same pattern of expression (Fig S5). Finally, we stably transfected the FLAG-HPV16 E7MYC expression construct into HeLa cells (which expresses HPV18 E7) and treated these cells with 16E7-specific siRNA, si16E7, and MG132 before using anti-FLAG to immunoprecipitate any resulting full length or 5' truncated E7. We observed truncated E7 protein only in cells treated with si16E7 but not in cells treated with control siRNA or untreated (Fig. 6). The products were specifically FLAG-E7 as no proteins were observed in HeLa cells expressing nontagged 16E7. Overall this data are consistent with the hypothesis that truncated E7 protein is translated from the 5' end of RNAi-cleaved mRNA.

\section{DISCUSSION}

Generally, short-interfering RNAs (siRNAs) are believed to trigger rapid mRNA degradation via cleavage within the binding region, but comprehensive studies have not yet been conducted to chase the cleavage intermediates to prove this point. Here, we have investigated the fate of HPV-16 E6/7 mRNA after treatment with homologous shRNAs and siRNAs in TC-1 and CaSki cervical cancer cells, respectively. By comparing the steady state levels, stability and translation profiles we show that RNAi treatment triggers neither rapid nor complete mRNA degradation. Rather it results in the generation of a 5' cleavage fragment that is more stable than its 3' counterpart, and this fragment is translated into C-terminally truncated protein products. To our knowledge, this is the first detailed study to show this phenomena. It also explains the mechanistic basis for our previously published work showing RNAi alters immune presentation of ovalbumin (OVA) by increasing the level of the CTL epitope found in the 5' end of RNAi- 
targeted mRNA (21). While our work here is only with HPV16 E6/7 mRNA, when combined with our previous work it suggests this phenomena may be a common attribute of all RNAi.

The E6/7 mRNA abundance was considerably repressed upon RNAi targeting but a corresponding reduction in the cleavage products was not observed (Fig. 1). The data showed that si/shRNA cleavage led to unequal degradation of the cleavage products, with higher steadystate levels of the 5' fragment. Moreover, qPCR data provided some initial clues about a progressive degradation reaction of the 3' fragment (Fig. 1D and 1E). The rationale behind such ambiguity remains largely undefined at this stage but it raises a possibility that the 5' fragment might be temporarily protected from exosome degradation. Indeed, previous observations support this. For example, cleavage mediated by perfectly complementary let-7 miRNA resulted in a stable 5' fragment lacking a poly(A) tail (17). However, others have shown that the 3' siRNA cleavage fragments persist after cleavage, although it was observed that this does not occur for all mRNAs for reasons not yet clear $(18,20)$.

The 5' cap and 3' poly(A) tail are critical for mRNA stability $(29,30)$ and translation (31), and the absence of any one of them alter mRNA turnover rates. We found that si/shRNAmediated cleavage leads to differential stability of cleavage products with the ${ }^{\prime}$ ' $\mathrm{mRNA}$ decay intermediate persisting in the cell longer than its 3' counterpart (Fig. 2C-2E). We speculate that the presence of cap structure, mRNA secondary structure and/or translation factors might block access to the exosome but this remains to be proven. A likely outcome of greater stability of the 5 ' fragment could be preferential translation into truncated protein. While we have previously shown that cleaved mRNA can be translated (21), it is not clear how this might occur. Moreover, efficient ribosome loading usually requires a cap and a poly(A) tail (31). Thus, it is difficult to envisage how a capped, but poly(A)-less, 5' fragment might be loaded onto the translation apparatus. One possibility is that cleavage might be occurring on already translating mRNA, perhaps in a manner similar to how miRNAs interact with mRNA $(32,33)$. We showed the 5' mRNA fragment was loaded on polysomes (Fig. 3 and 4). This suggests that mRNA may enter the RNAi pathway at a stage closer to translation, when the ribosomes are already bound to the mRNA. This is consistent with the previous observation in Drosophila S2 cells, which showed that 5' mRNA fragments generated as a result of double-stranded RNA (dsRNA) cleavage were translated prior to their decay (5). The 5' cleavage products should, theoretically, be in frame but lack a stop codon; resembling aberrant transcripts that are recognized and targeted for 
destruction by the non-stop decay (NSD) mechanism (34). Given that NSD events take place on polysomes (34) it is likely that translationally dead-end 5' fragments could give rise to Cterminally truncated protein products. This idea is consistent with the presence of increased levels of FLAG-tagged truncated protein products in RNAi treated cells (Fig. 5 and 6). At this stage it is difficult to say whether translation of the 5' fragment is a result of its higher stability or whether its association with the translation machinery offers a steric hindrance to the exosome, thus, making it more stable. Previous studies using antisense oligonucleotides have shown that RNase H-generated 3' cleavage intermediates are translated into N-terminally truncated proteins $(35,36)$, contradictory to what our findings indicate for the fate of Ago2generated cleavage intermediates, but, mechanistic differences exist between antisense- and RNAi-mediated endonucleolysis.

Our results suggest possibly two distinct models by which siRNA silencing might affect the cytoplasmic mRNA levels. The first model is that such translation could occur via transport of RNAi-cleaved 5' fragments from P-bodies (PBs) to polysomes, a model consistent with previous studies showing full-length mRNA can do this (15). Spatial organization in P-bodies may selectively render the 3' fragments susceptible to XRN1 degradation. Support for this idea is lent by studies showing co-localisation of XRN1 (but not the exosome components) with PBs (37). The alternative model is that siRISC assembly and mRNA cleavage occurs directly on the translating mRNA pool. In support of this argument, Ago1, in the context of miRNAs has been found associated with polysomes in mammalian cells (38-40). Since translation has already begun at the 5' end, post cleavage ribosomes would complete the round of translation and stall at the 3' end of the 5' fragment, as described for NSD. In order to release the occupied ribosomes for cellular protein synthesis, such fragments may be subjected to exosome degradation (41). This is also consistent with the observed stabilization of the 5' fragment (Fig. 2) where the presence of translation factors/ribosomes might block access to the exosome. One major question that remains unresolved is whether Ago2 cleavage occurs on nascent mRNA in cytoplasm, on siRNA bound non-translating mRNPs in PBs or else on polysome bound mRNAs in the cytoplasm. Alternatively, siRNA silencing might be a combined outcome of such events.

It is known that plants utilize RNA silencing pathways to directly respond to virus attack. Mammals having evolved an elaborate immune system do not appear to use the RNAi machinery to directly respond to pathogens or tumours. However, our previous work has shown that C- 
terminally truncated proteins behave as gain-of-function mutants and RNAi, if appropriately targeted, can augment the immune surveillance mechanisms already in place (21). Thus, the RNAi system may directly influence immunity to target proteins. Having established these insights we can now focus on consequences of RNAi-directed production of truncated protein products in other biological systems, including potential dominant negative effects. In conclusion, selective stabilization and translation of the 5' mRNA fragment suggest that siRNA targeted mRNA enter into an uncharacterized decay pathway. While further work is required, our study provides a novel insight into RNAi, particularly into the way in which mRNA is fed into the siRNA pathway for posttranscriptional gene regulation.

\section{Acknowledgements.}

We thank Dr. Sandrine Roy (The University of Queensland Diamantina Institute, Brisbane, QLD) for assistance with confocal microscopy.

\section{References}

1. Elbashir SM, Lendeckel W, \& Tuschl T (2001) RNA interference is mediated by 21-and 22-nucleotide RNAs. Genes Dev 15(2):188-200.

2. Martinez J, Patkaniowska A, Urlaub H, Luhrmann R, \& Tuschl T (2002) Single-stranded antisense siRNAs guide target RNA cleavage in RNAi. Cell 110(5):563-574.

3. Garneau NL, Wilusz J, \& Wilusz CJ (2007) The highways and byways of mRNA decay. Nat Rev Mol Cell Biol 8(2):113-126.

4. Parker R \& Song H (2004) The enzymes and control of eukaryotic mRNA turnover. Nat Struct Mol Biol 11(2):121-127.

5. Orban TI \& Izaurralde E (2005) Decay of mRNAs targeted by RISC requires XRN1, the Ski complex, and the exosome. Rna-a Publication of the Rna Society 11(4):459-469. 
6. Shen B \& Goodman HM (2004) Uridine addition after microRNA-directed cleavage. Science 306(5698):997.

7. Souret FF, Kastenmayer JP, \& Green PJ (2004) AtXRN4 degrades mRNA in Arabidopsis and its substrates include selected miRNA targets. Mol Cell 15(2):173-183.

8. Parker R \& Sheth U (2007) P bodies and the control of mRNA translation and degradation. Mol Cell 25(5):635-646.

9. Eulalio A, Behm-Ansmant I, \& Izaurralde E (2007) P bodies: at the crossroads of posttranscriptional pathways. Nat Rev Mol Cell Biol 8(1):9-22.

10. Liu J, et al. (2005) A role for the P-body component GW182 in microRNA function. Nature cell biology 7(12):1261-1266.

11. Jakymiw A, et al. (2005) Disruption of GW bodies impairs mammalian RNA interference. Nature cell biology 7(12):1267-1274.

12. Eulalio A, Behm-Ansmant I, Schweizer D, \& Izaurralde E (2007) P-body formation is a consequence, not the cause, of RNA-mediated gene silencing. Mol Cell Biol 27(11):3970-3981.

13. Teixeira D, Sheth U, Valencia-Sanchez MA, Brengues M, \& Parker R (2005) Processing bodies require RNA for assembly and contain nontranslating mRNAs. Rna 11(4):371-382.

14. Cougot N, Babajko S, \& Seraphin B (2004) Cytoplasmic foci are sites of mRNA decay in human cells. J Cell Biol 165(1):31-40.

15. Brengues M, Teixeira D, \& Parker R (2005) Movement of eukaryotic mRNAs between polysomes and cytoplasmic processing bodies. Science 310(5747):486-489.

16. Anderson P \& Kedersha N (2006) RNA granules. J Cell Biol 172(6):803-808.

17. Chen CYA, Zheng DH, Xia ZF, \& Shyu AB (2009) Ago-TNRC6 triggers microRNAmediated decay by promoting two deadenylation steps. Nat Struct Mol Biol 16(11):1160-U1166.

18. Holmes K, Williams CM, Chapman EA, \& Cross MJ (2010) Detection of siRNA induced mRNA silencing by RT-qPCR: considerations for experimental design. BMC Res Notes 3:53. 
19. Zeng Y, Yi R, \& Cullen BR (2003) MicroRNAs and small interfering RNAs can inhibit mRNA expression by similar mechanisms. Proc Natl Acad Sci U S A 100(17):9779-9784.

20. Holen T, Amarzguioui M, Wiiger MT, Babaie E, \& Prydz H (2002) Positional effects of short interfering RNAs targeting the human coagulation trigger Tissue Factor. Nucleic Acids Res 30(8):1757-1766.

21. Gu W, et al. (2009) Both treated and untreated tumors are eliminated by short hairpin RNA-based induction of target-specific immune responses. Proc Natl Acad Sci U S A 106(20):8314-8319.

22. Clancy JL, et al. (2007) Methods to analyze microRNA-mediated control of mRNA translation. Methods Enzymol 431:83-111.

23. Chen C, et al. (2005) Real-time quantification of microRNAs by stem-loop RT-PCR. Nucleic Acids Res 33(20):e179.

24. Jeon S, Allen-Hoffmann BL, \& Lambert PF (1995) Integration of human papillomavirus type 16 into the human genome correlates with a selective growth advantage of cells. $J$ Virol 69(5):2989-2997.

25. Luczak MW \& Jagodzinski PP (2008) Apicidin down-regulates human papillomavirus type 16 E6 and E7 transcripts and proteins in SiHa cervical cancer cells. Cancer Lett 272(1):5360 .

26. Cheng A, et al. (2009) Stem-loop RT-PCR quantification of siRNAs in vitro and in vivo. Oligonucleotides 19(2):203-208.

27. Schubert U, et al. (2000) Rapid degradation of a large fraction of newly synthesized proteins by proteasomes. Nature 404(6779):770-774.

28. Knapp AA, McManus PM, Bockstall K, \& Moroianu J (2009) Identification of the nuclear localization and export signals of high risk HPV16 E7 oncoprotein. Virology 383(1):6068 .

29. Bernstein P \& Ross J (1989) Poly(A), poly(A) binding protein and the regulation of mRNA stability. Trends Biochem Sci 14(9):373-377. 
30. Shimotohno K, Kodama Y, Hashimoto J, \& Miura KI (1977) Importance of 5'-terminal blocking structure to stabilize mRNA in eukaryotic protein synthesis. Proc Natl Acad Sci U S A 74(7):2734-2738.

31. Preiss T \& Hentze MW (1998) Dual function of the messenger RNA cap structure in poly(A)-tail-promoted translation in yeast. Nature 392(6675):516-520.

32. Djuranovic S, Nahvi A, \& Green R (2012) miRNA-mediated gene silencing by translational repression followed by mRNA deadenylation and decay. Science 336(6078):237240.

33. Bethune J, Artus-Revel CG, \& Filipowicz W (2012) Kinetic analysis reveals successive steps leading to miRNA-mediated silencing in mammalian cells. EMBO Rep 13(8):716-723.

34. Frischmeyer PA, et al. (2002) An mRNA surveillance mechanism that eliminates transcripts lacking termination codons. Science 295(5563):2258-2261.

35. Hasselblatt P, Hockenjos B, Thoma C, Blum HE, \& Offensperger WB (2005) Translation of stable hepadnaviral mRNA cleavage fragments induced by the action of phosphorothioatemodified antisense oligodeoxynucleotides. Nucleic Acids Res 33(1):114-125.

36. Thoma C, et al. (2001) Generation of stable mRNA fragments and translation of Ntruncated proteins induced by antisense oligodeoxynucleotides. Mol Cell 8(4):865-872.

37. Sheth U \& Parker R (2003) Decapping and decay of messenger RNA occur in cytoplasmic processing bodies. Science 300(5620):805-808.

38. Nottrott S, Simard MJ, \& Richter JD (2006) Human let-7a miRNA blocks protein production on actively translating polyribosomes. Nat Struct Mol Biol 13(12):1108-1114.

39. Kim J, et al. (2004) Identification of many microRNAs that copurify with polyribosomes in mammalian neurons. Proc Natl Acad Sci U S A 101(1):360-365.

40. Nelson PT, Hatzigeorgiou AG, \& Mourelatos Z (2004) miRNP:mRNA association in polyribosomes in a human neuronal cell line. Rna 10(3):387-394. 
41. van Hoof A, Frischmeyer PA, Dietz HC, \& Parker R (2002) Exosome-mediated recognition and degradation of mRNAs lacking a termination codon. Science 295(5563):22622264. 


\section{FIGURE LEGENDS}

Fig 1. shRNA cleaved mRNA is not evenly degraded. Total RNA samples were isolated from control (untreated and non-specific shRNA, shNS-1) or E6/7 targeting shRNA (shE6 and shE7) treated TC-1 cells, and analyzed by semi-quantitiative RT-PCR and quantitative RT-PCR (qPCR) to assess the levels of 5' and 3' ends of E6/7 mRNA. (A) Schematic representation of the cutsites of E6/7 specific-shRNAs and PCR amplicons amplifying different regions of E6/7 mRNA. (B) Representative gel image of semi-quantitiative RT-PCR products (Primer scheme B). (C) Steady-state levels of the 5' and 3' ends of E6/7 mRNA determined by absolute qPCR (Primer scheme C). (D) Abundance of different regions of 5' fragment created after shE7 cleavage by absolute qPCR (Primer scheme D). (E) Abundance of different regions of 3' fragment created after shE6 cleavage by absolute qPCR (Primer scheme E). Mean \pm SEM; $n=3$.

Fig 2. The 5' cleavage product is more stable than the 3' cleavage product in shRNA treated cells. Decay profiles of the full-length E6/7 mRNA (A) and the 5' and 3' ends of E6/7 mRNA in TC-1 cells treated with non-specific shRNA, shNS-1 (B); and E6/7 specific shRNAs, shE6 and shE7 (C). Cells were cultured for indicated time points in the presence of actinomycin D (Act D, $5 \mu \mathrm{g} / \mathrm{mL}$ ) prior to harvesting for RNA extraction. E6/7 mRNA expression was analysed by qPCR ( $\Delta \Delta \mathrm{Ct}$ method), relative to untreated $0 \mathrm{~h}$ sample and normalized against housekeeping gene, $\beta$ actin. Primers described in Fig. 1A [amplicons 6/7 (full-length mRNA), 4 (5' end) and 5 (3' end)] were utilized for qPCR. E6/7 mRNA expression at $0 \mathrm{~h}$ time-point was set to $100 \%$ in each individual experiment to determine half-life values. The graphs show the percentage of mRNA remaining ( $y$-axis) plotted against time post Act D treatment ( $x$-axis). Mean $\pm \mathrm{SEM} ; \mathrm{n}=3$. Pvalue $<0.001(* *)$ or $<0.0001(* * *)$, comparing each treatment to shNS-1 controls (A) or between the 5' and 3' ends of each treatment $(\mathrm{C})$.

Fig 3. The 5' cleavage product is associated with polysomes. (A) Representative polyribosomal profiles of TC-1 cells treated with non-specific shRNA, shNS-1 and E6 targeting shRNA, shE6. Cytoplasmic lysates, prepared from cells treated with cycloheximide (CHX) were fractionated on a sucrose density gradient. Absorbance was recorded at $254 \mathrm{~nm}$ during collection of each 
fraction (B) Relative distributions of the 5' and 3' ends of E6/7 mRNA in gradient fractions of CHX treated shNS-1 and shE6 treated TC-1 cells. Each fraction was processed for RNA extraction and subsequently analysed by relative qPCR ( $\Delta \Delta \mathrm{Ct}$ method) utilizing 5' and 3' reporter primers, described in Fig. 1A (amplicons 4 and 5). The amount of E6/7 mRNA in each fraction was relative to the amount of spike-in RNA (in vitro transcribed B. subtilis RNA). Mean $\pm \mathrm{SEM} ; \mathrm{n}=1$, three technical replicates. $\mathrm{P}$-value $<0.0001$ (***) comparing the 5 ' and 3 ' ends of each treatment.

Fig 4. The specific 5' cleavage product can be detected in total and polysomal RNA by stemloop qPCR. (A) Schematic depicting Taqman based stem-loop RT-PCR strategy to detect the presence of 5' cleavage products. Total or polysomal RNA (500 ng) was reverse transcribed using a stem loop RT primer that binds specifically to the last 4 nucleotides on 3' end of the 5' cleavage fragment. The PCR product was amplified from cDNA using Taqman probe and primers. (B) Stem loop qPCR detection of 5' cleavage product in positive control, negative controls (untreated and non-specific shRNA, shNS-1) and shE6 treated TC-1 cells. The positive control sample was prepared by digesting pcDNA3-16E7 plasmid with BanII, followed by in vitro transcription to generate a fragment resembling the 5' cleavage product. NTC - no template control. P-value $<0.0001(* * *)$, comparing each treatment to the positive control

Fig 5. C-terminally truncated proteins can be detected in shRNA treated cells. (A) Schematic depicting E7 gene tagged with FLAG tag on the 5' end and MYC tag on the 3' end. The FLAGE7-MYC construct was cloned into pcDNA3 for transient transfections. The cutsite of E7specific shRNA, shE7 has been indicated. (B) The expression of FLAG-E7-MYC protein in TC1 cell lines stably expressing pLL 3.7 vector only (empty vector); non-specific shRNAs, shNS-1 and shNS-2; and shE7. The FLAG and MYC protein expression was visualised by confocal microscopy, using FLAG (red fluorophore, Alexa Fluor 555) and MYC (green fluorophore, Alexa Fluor 647) antibodies. Magnified images of shNS-1 and shE7 expressing TC-1 cells are shown. The images are representative of at least 25-50 individual cells. Scale bars $=10 \mu \mathrm{m}$. (C) The ratio of FLAG (C-terminal) to MYC (N-terminal) expression in the nuclei of silenced cells 
transiently transfected with pcDNA3 FLAG-E7-MYC construct. The nuclear intensities of FLAG and MYC signals were measured by ImageJ software and FLAG/MYC ratio was calculated. Mean \pm SEM; $\mathrm{n}>40$. P-value <0.0001 (***), compared to shNS-2.

Fig 6. Detection of truncated protein in siRNA-treated cells. HeLa cells were stably transfected with either HPV16E7 or FLAG-HPV16E7-MYC before being treated with siRNAs (40nM of si16E7 or controls) and the proteosomal inhibitor, MG132, before protein extraction. FLAG16E7-Myc was immunoprecipitated and detected with anti-FLAG antibodies. Size markers are indicated and a FLAG positive control protein is shown in lane 1.

\section{Supporting Information}

S1 Fig. siRNA cleaved mRNA is not evenly degraded. (A) Schematic representation of the cutsite of E7 specific siRNA, siE7 and PCR amplicons amplifying the 5' and 3' ends of E6/7 mRNA. (B) Total RNA was extracted from control (untreated and non-targeting siRNA, siNS-1) or siE7 treated CaSki cells and analysed by relative quantitative RT-PCR ( $\Delta \Delta \mathrm{Ct}$ method). Pvalue $<0.01(* *)$.

S2 Fig. The 5' cleavage product is more stable than the 3' cleavage product in siRNA treated cells. qRT-PCR analysis of degradation kinetics of 5' and 3' ends of E6/7 mRNA in untreated (A); non-specific siRNA, siNS-1 (B); and E7 specific siRNA, siE7 (C) treated CaSki cells. After incubation in Actinomycin D (ActD) containing medium $(5 \mu \mathrm{g} / \mathrm{mL})$ for indicated time points, the levels of 5' and 3' ends of E6/7 mRNA were measured to determine their half-lives. The $y$ axis depicts relative E6/7 mRNA expression. The $x$ axis represents the time (h) after the addition of ActD. Mean \pm SEM; $n=3$. The half-lives of 5' and 3' ends of the E6/7 mRNA are similar in untreated CaSki cells. Although half-lives of 5' and 3' ends appear to be similar in case of siNS1 treatment, the exact values remain undetermined. The 5' E6/7 mRNA fragment was at least 
two times more stable when compared to the corresponding 3' fragment in cells transfected with siE7.

S3 Fig. EDTA treatment dissociates polyribosome assembly from E6/7 mRNA. Cytoplasmic lysates were prepared from cells treated with EDTA and fractionated on a sucrose density gradient. (A, B) Representative polyribosomal profiles of non-specific shRNA, shNS-1 and E6/7 targeting shRNA, shE6 treated TC-1 cells. Absorbance was recorded at $254 \mathrm{~nm}$ during collection of each fraction. (C) Relative distribution of $\beta$-actin mRNA in cycloheximide (CHX) and EDTA treated TC-1 cells. Each fraction was processed for RNA extraction and subsequently analysed by qPCR. The amount of $\beta$-actin mRNA in each fraction is relative to the amount of spike-in RNA (in vitro transcribed B. subtilis $\mathrm{RNA}$ ). Mean $\pm \mathrm{SEM} ; \mathrm{n}=3$.

S4 Fig. Full-length E6/7 is bound to less number of ribosomes. Relative distribution of the full length E6/7 mRNA in gradient fractions of cycloheximide treated shNS-1 (A) and shE6 (B) treated TC-1 cells. Each fraction was processed for RNA extraction and subsequently analysed by relative qPCR ( $\Delta \Delta \mathrm{Ct}$ method) utilizing amplicon 6 described in Fig. 1A. The amount of E6/7 mRNA in each fraction was relative to the amount of spike-in RNA (in vitro transcribed $B$. subtilis $\mathrm{RNA})$. Mean $\pm \mathrm{SEM} ; \mathrm{n}=3$.

S5 Fig. C-terminally truncated proteins can be detected in siRNA treated cells. (A) Schematic depicting E7 gene tagged with FLAG tag on the 5' end and MYC tag on the 3' end. The cutsite of E7-specific siRNAs, siE7 and siE7 new have been indicated. (B) Confocal images of FLAG and MYC protein expression in control and treated cells. The pcDNA3 FLAG-E7-MYC construct was transiently expressed in TC-1 cells prior to transfection with E7 specific siRNAs, siE7 and siE7 new. Scale bars $=10 \mu \mathrm{m}$. The images are representative of at least 25 individual cells. (C) The nuclear intensities of FLAG and MYC signals were measured by ImageJ software and FLAG/MYC ratio in control and siRNA treated cells was calculated. Mean \pm SEM; $n>40$. P-values $<0.0001(* * *)$, compared to siNS-1.

\section{Supporting Tables.}

Table $\mathbf{S 1}$ sh/siRNA target sites and sequences. 
Table S2 Primer sequences used for real-time quantitative RT-PCR analysis

Table S3 Primer and probe sequences used for stem loop qPCR analysis 
Fig 1

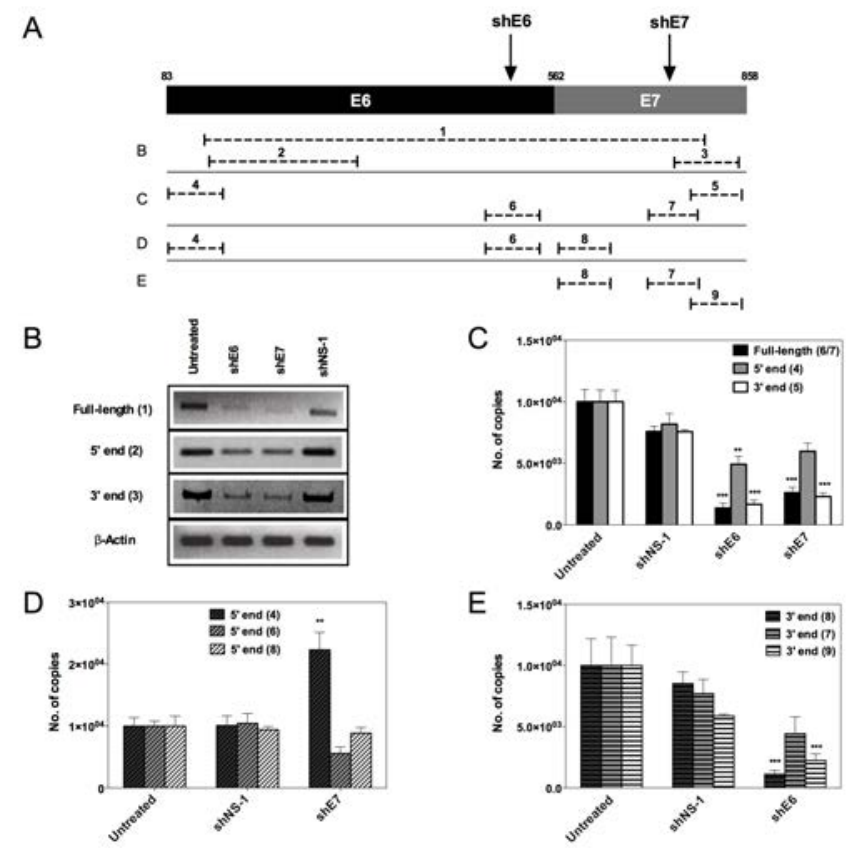


Fig 2

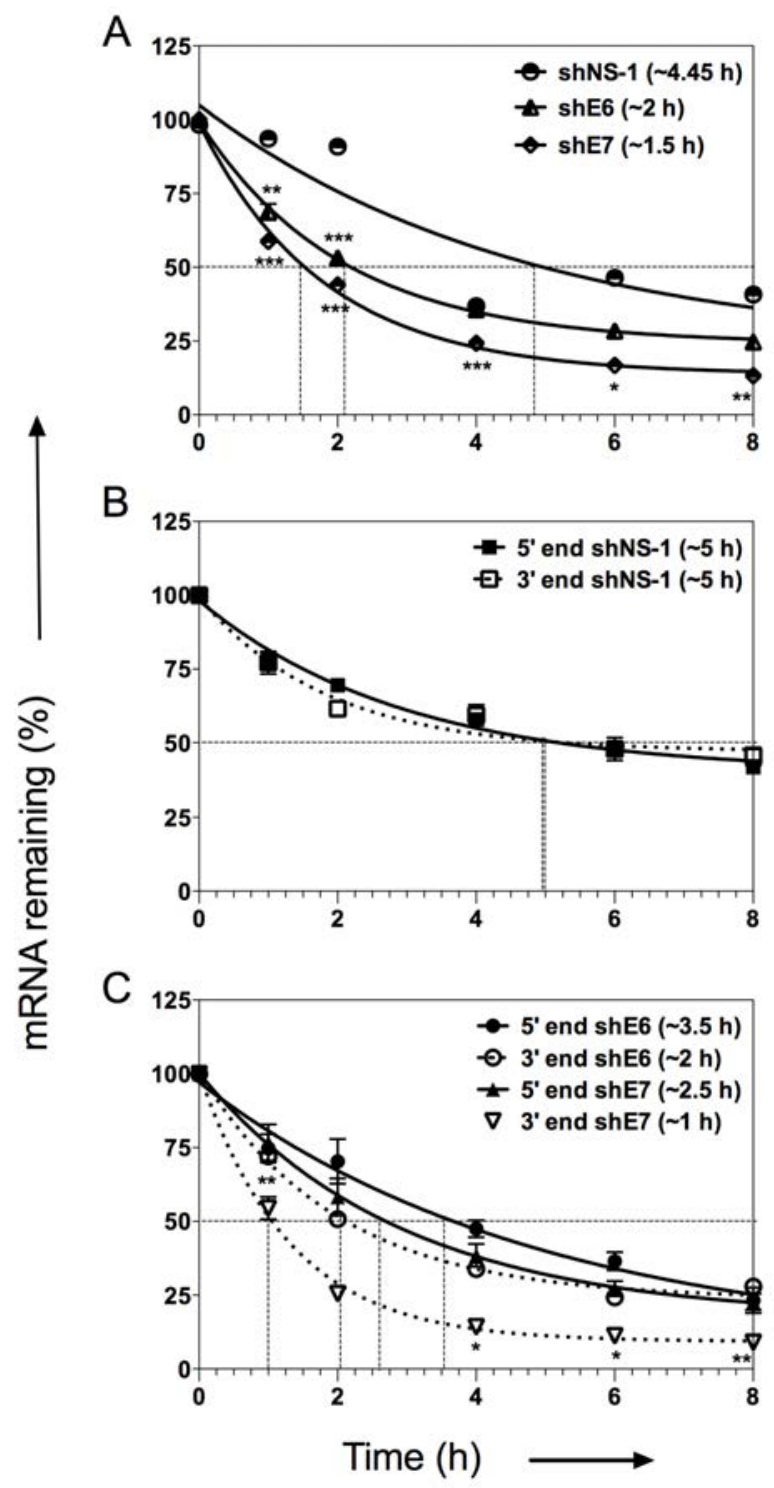


Fig 3

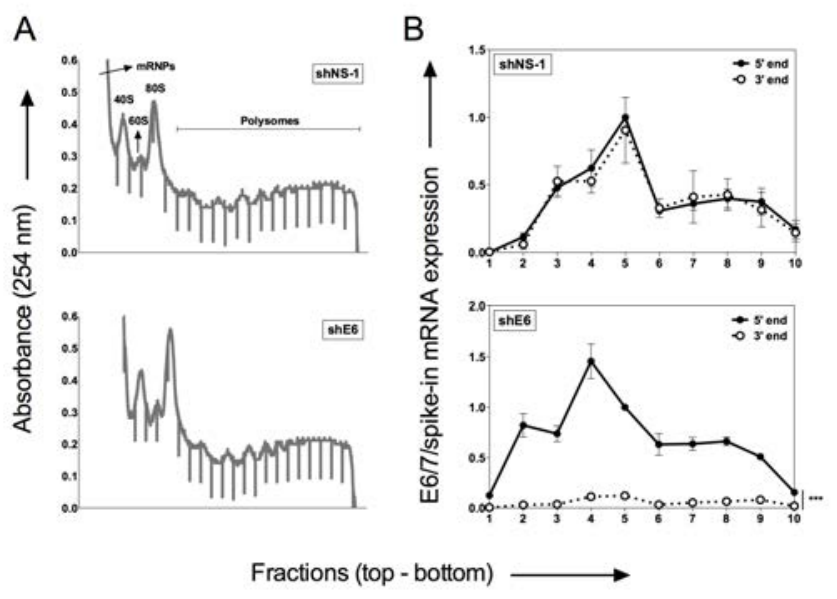


Fig 4
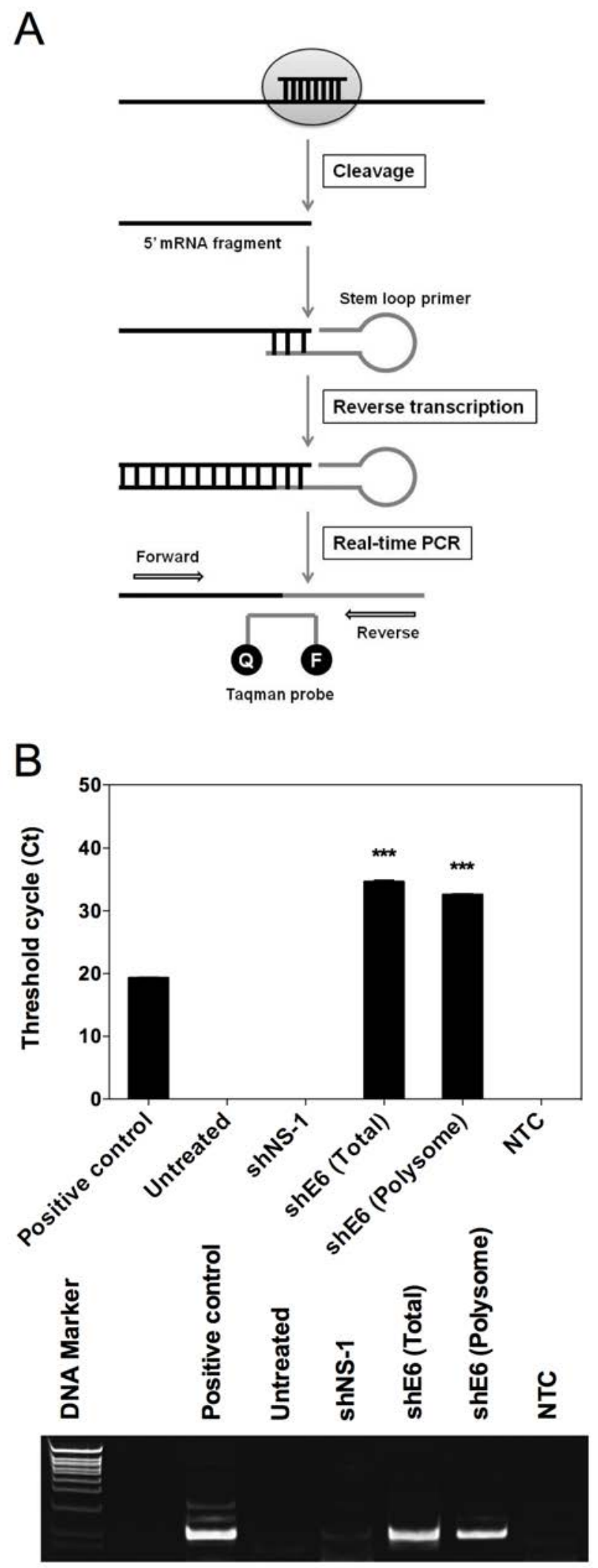
Fig 5

A

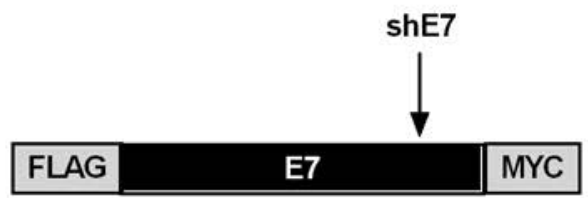

C

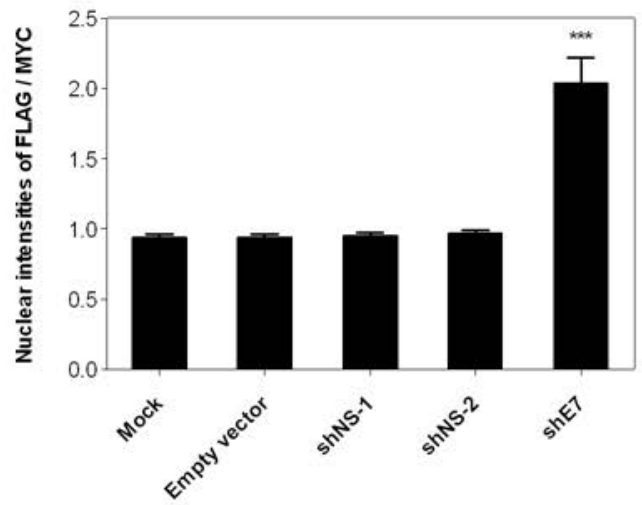

B

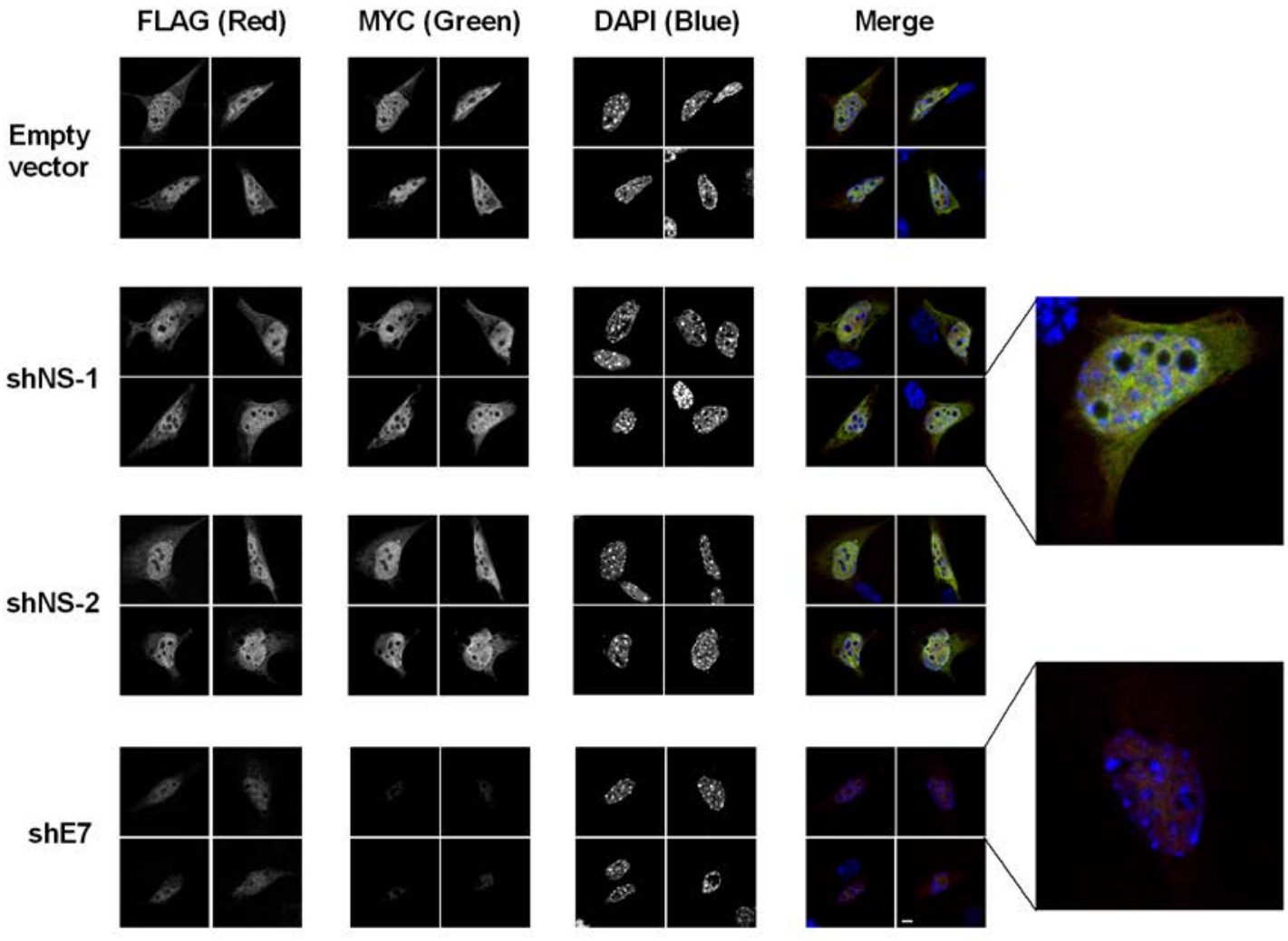


Fig 6

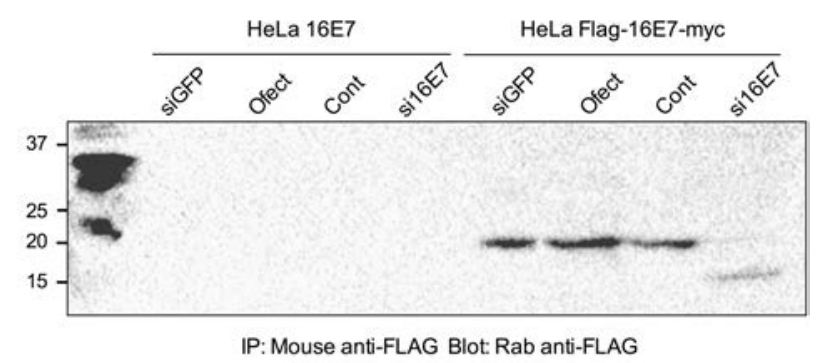


Fig S1

A

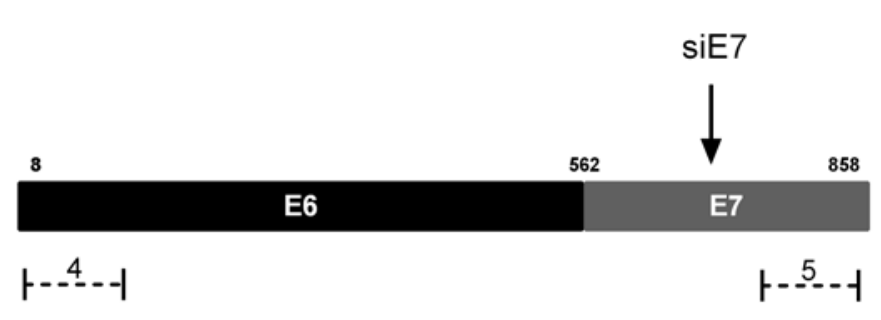

B

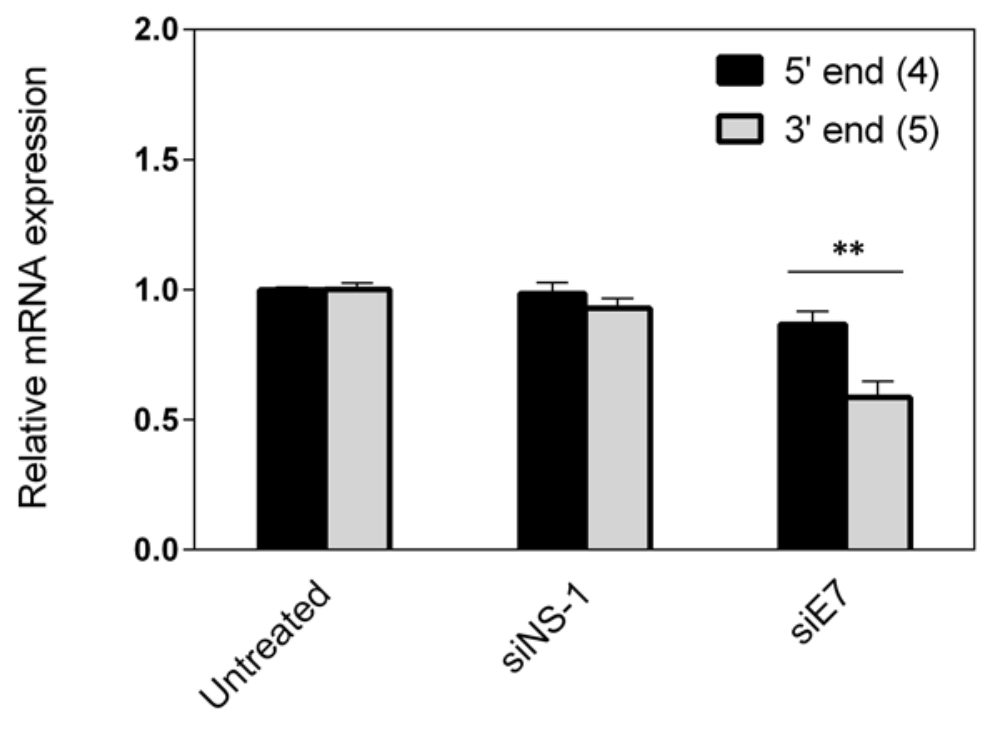


Fig S2

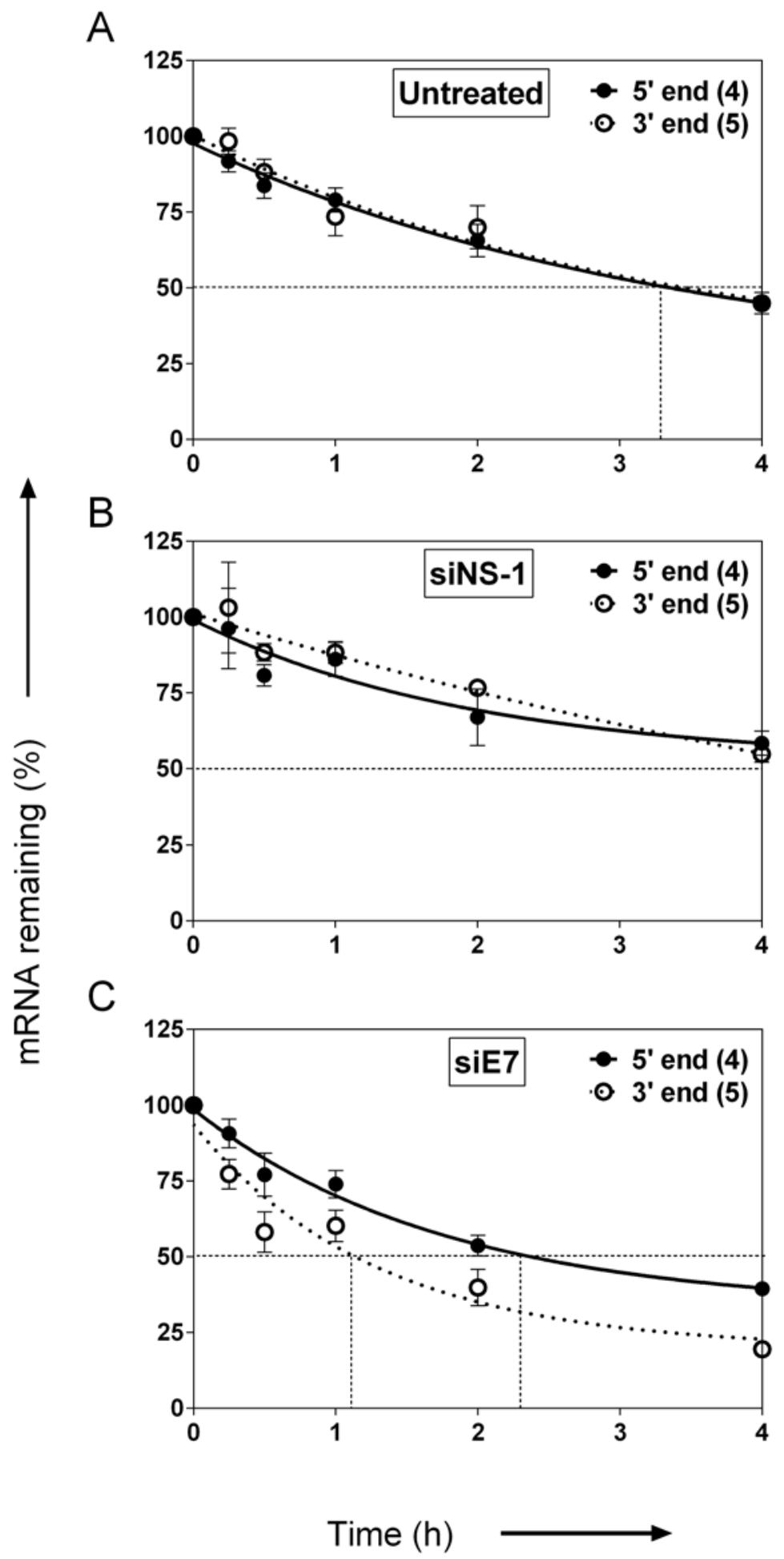


Fig S3

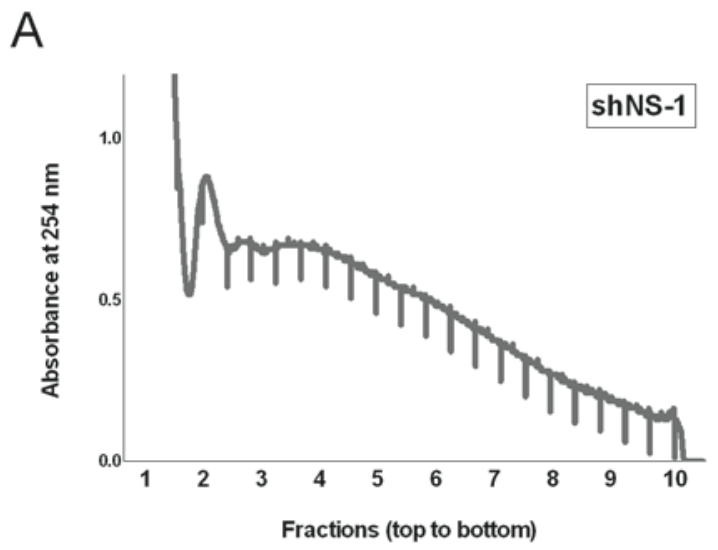

B

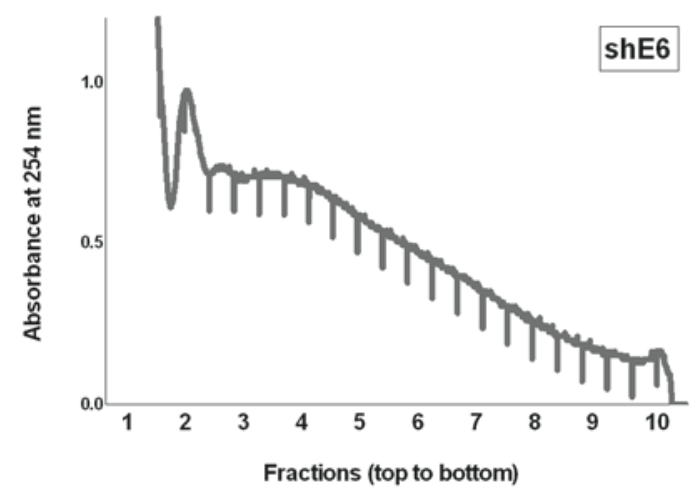

C

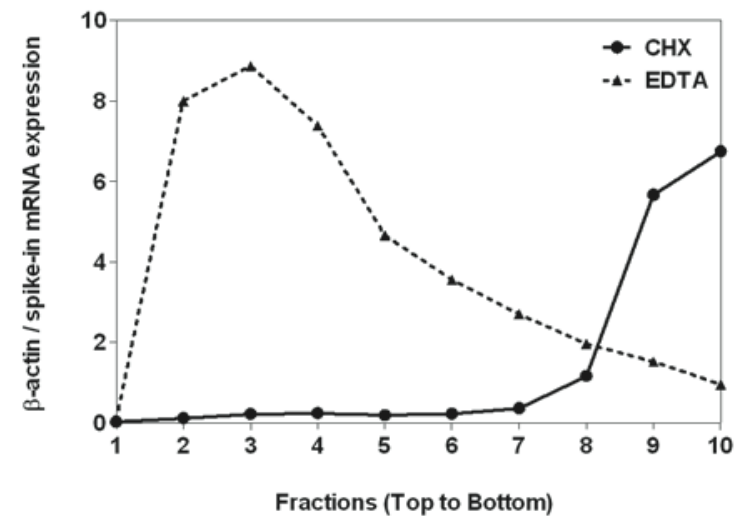


Fig S4

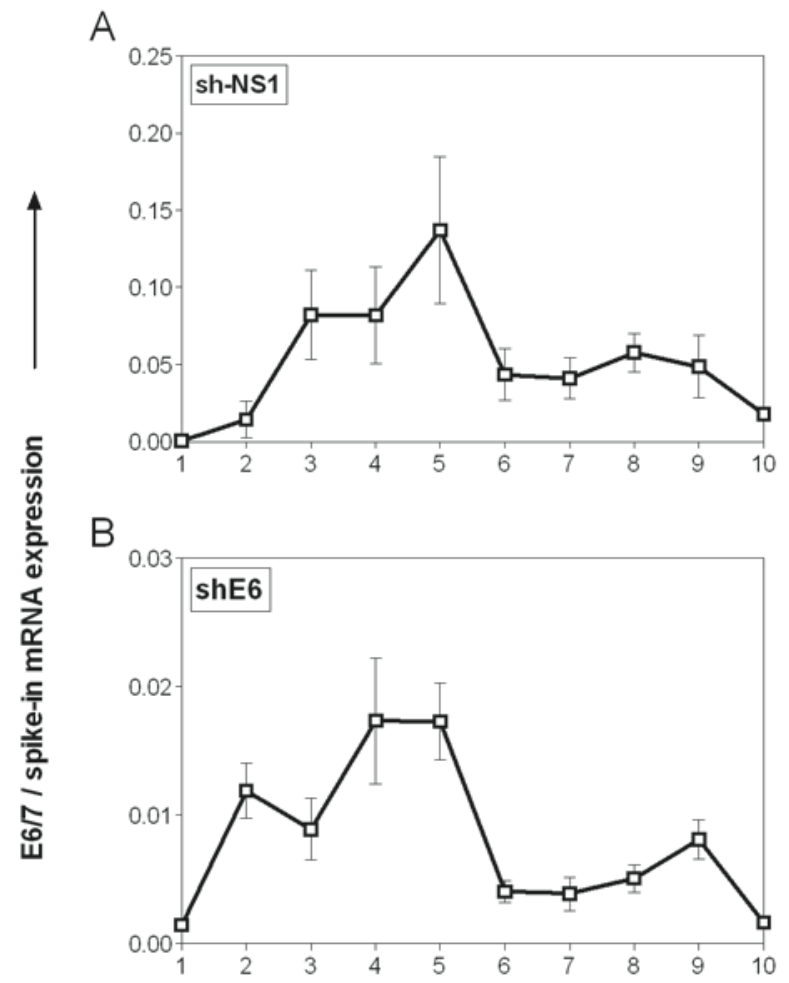

Fractions (top - bottom) 
Fig S5

A

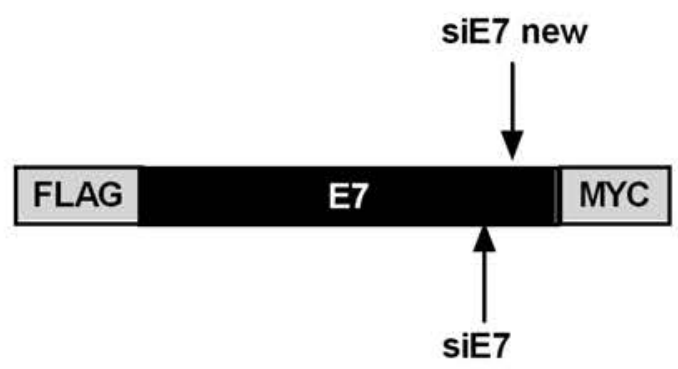

C

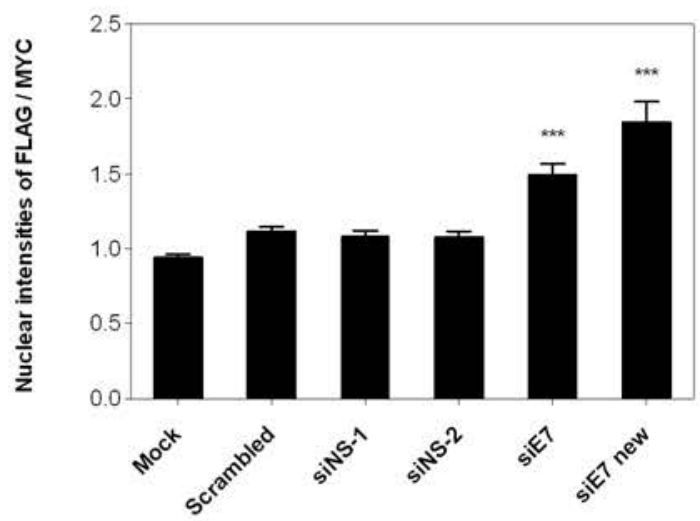

B

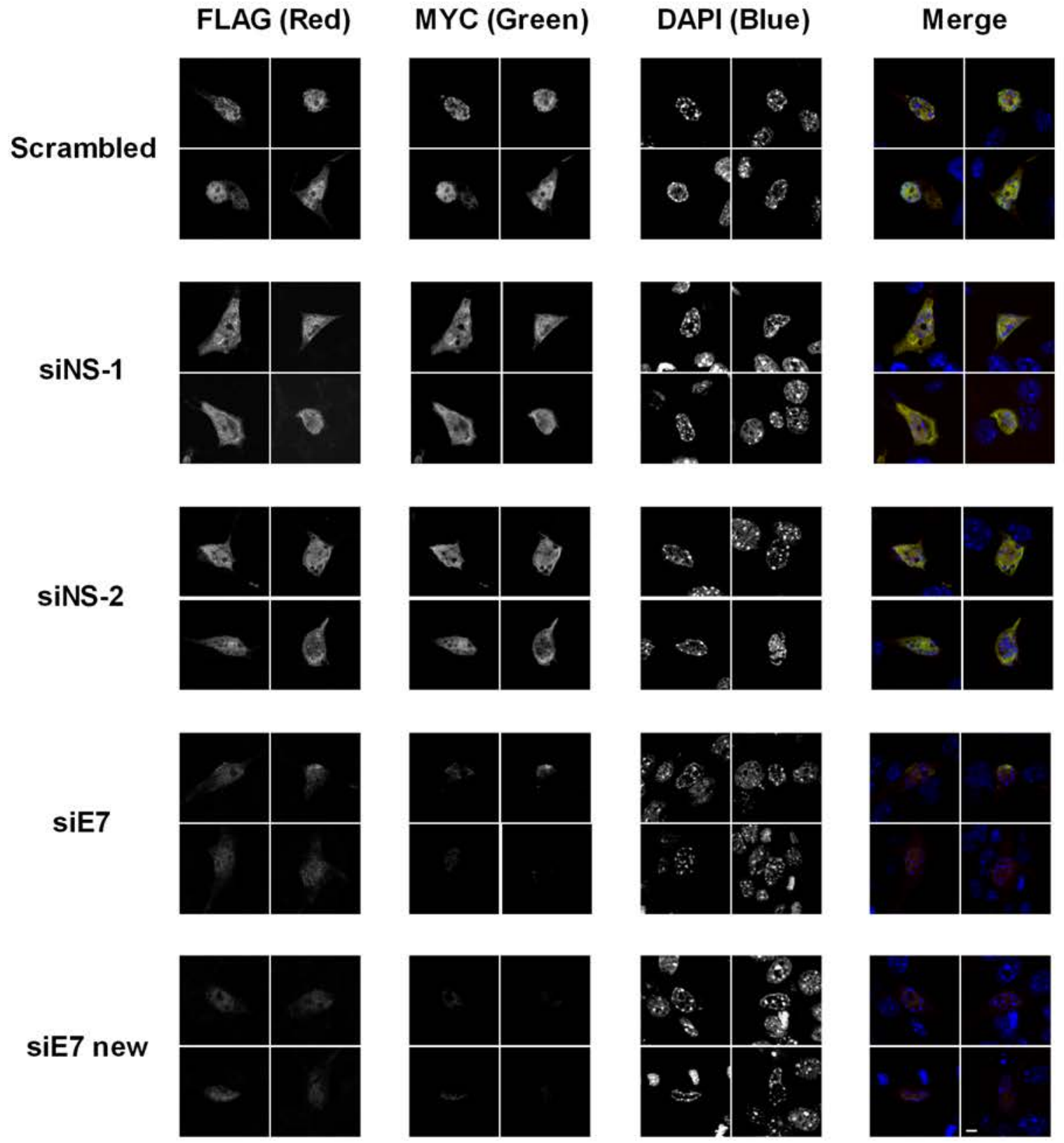


Table S1 sh/siRNA target sites and sequences

\begin{tabular}{|c|c|c|}
\hline sh/siRNA & Target sequence & Target site in HPV16 E6/7 \\
\hline shE6 & GACCGGTCGATGTATGTC & $417-434$ \\
\hline shE7 & GTGTGACTCTACGCTTCGG & $659-677$ \\
\hline shNS-1 & ACCAAATGATGTTTATTCGT & shRNA against OVA \\
\hline shNS-2 & AGGTATTTGAATTTGCAT & shRNA against HPV-18 E6 \\
\hline siE6 & AAGCAACAGTTACTGCGACGT & $120-141$ \\
\hline SiE7 & GAACCGGACAGAGCCCATTACAATATT & $617-644$ \\
\hline siE7 new & GTACAAAGCACACACGTAGACATTCGT & $686-713$ \\
\hline siNS-1 & CCTGAACTTCTTCAGCACGAA & siRNA against GFP \\
\hline siNS-2 & AATTATGCCGATCGCGTCACA & siRNA against $\beta$-gal \\
\hline Scrambled & CAGCAAUUAGCGCAUAUUAUGCGCAUA & No target \\
\hline
\end{tabular}


Table S2 Primer sequences used for real-time quantitative RT-PCR analysis

\begin{tabular}{|c|c|c|}
\hline Primer & Sequence (5'-3' direction) & $\begin{array}{l}\text { Amplicon size } \\
\text { (bp) }\end{array}$ \\
\hline $1 \mathrm{~F}$ & TTGCTTTTCGGGATTTATGC & 593 \\
\hline $1 R$ & CAATTCCTAGTGTGCCCAT & \\
\hline $2 F$ & TTGCTTTTCGGGATTTATGC & 202 \\
\hline $2 \mathbf{R}$ & GGACACAGTGGCTTTTGAC & \\
\hline $3 F$ & AAGCACACACGTAGACATTCG & 88 \\
\hline $3 R$ & TTATGGTTTCTGAGAACAGATGG & \\
\hline $4 \mathrm{~F}$ & GAGCGACCCAGAAAGTTACC & 137 \\
\hline $4 R$ & ATGCATAAATCCCGAAAAGC & \\
\hline $5 F$ & TGCGTACAAAGCACACACG & 93 \\
\hline $5 R$ & TGGTTTCTGAGAACAGATGG & \\
\hline $6 \mathrm{~F}$ & CTGGACAAAAAGCAAAGATTCC & 115 \\
\hline $6 \mathrm{R}$ & TCTCCATGCATGATTACAGC & \\
\hline $7 \mathrm{~F}$ & CAGCTGGACAAGCAGAACC & 135 \\
\hline $7 \mathbf{R}$ & TGCCCATTAACAGGTCTTCC & \\
\hline $8 \mathrm{~F}$ & TTGCAGATCATCAAGAACACG & 108 \\
\hline $8 R$ & GAGATCAGTTGTCTCTGGTTGC & \\
\hline $9 \mathrm{~F}$ & CGGACAGAGCCCATTACAATA & 158 \\
\hline $9 \mathrm{R}$ & TTATGGTTTCTGAGAACAGATGG & \\
\hline Mu b-actin-F & GCTACAGCTTCACCACCACA & 123 \\
\hline Mu b-actin-R & TCTCCAGGGAGGAAGAGGAT & \\
\hline Mu-18S F & AGTCCCTGCCCTTTGTACACA & 70 \\
\hline Mu-18S R & CGATCCGAGGGCCTCACTA & \\
\hline Human b-actin F & АСTCTTCCAGCCTTCCTTCC & 109 \\
\hline Human b-actin $\mathbf{R}$ & GTTGGCGTACAGGTCTTTGC & \\
\hline Human 18S F & GCAATTATTCCCCATGAACG & 125 \\
\hline Human 18S R & AGGGCCTCACTAAACCATCC & \\
\hline
\end{tabular}


Table S3 Primer and probe sequences used for stem loop qPCR analysis

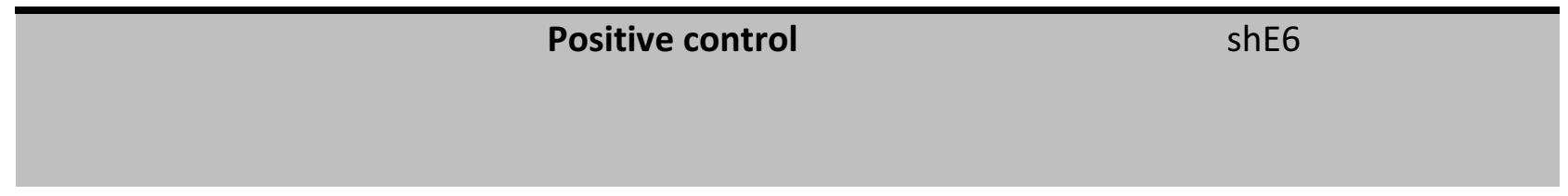

\begin{tabular}{lcc}
$\begin{array}{l}\text { Stem loop RT } \\
\text { primer }\end{array}$ & $\begin{array}{l}\text { GTCGTATCCAGTGCAGGGTCCGAGG } \\
\text { TATTCGCACTGGATACGACGGCTCT }\end{array}$ & $\begin{array}{c}\text { GTCGTATCCAGTGCAGGGTCCGAGG } \\
\text { TATTCGCACTGATACGACTCGACC }\end{array}$ \\
Forward Primer & GGAGGAGGATGAAATAGATGG & TGGACAAAAAGCAAAGATTCC \\
$\begin{array}{l}\text { Taqman Probe } \\
\text { (6-FAM)CAGCTGGACAAGCAG } \\
\text { AACCGGA(BHQ-1) }\end{array}$ & $\begin{array}{c}\text { (6-FAM)TGGACCGGTCGAGTC } \\
\text { GTATCCA(BHQ-1) }\end{array}$ \\
$\begin{array}{l}\text { Universal reverse } \\
\text { primer }\end{array}$ & GTGCAGGGTCCGAGGT & GTGCAGGGTCCGAGGT \\
\hline
\end{tabular}

